\title{
An exploratory study of older customers' holistic supermarket shopping experience in China
}

\author{
YIN Yuanyuan ${ }^{a^{*}} ;$ SONG Qiu ${ }^{b}$ and RANCHHOD Ashok ${ }^{a}$ \\ ${ }^{a}$ Winchester School of Art, University of Southampton, United Kingdom \\ ${ }^{\mathrm{b}}$ Academy of Arts \& Design, Tsinghua University, China \\ *y.yin@soton.ac.uk \\ doi: 147
}

This research investigated difficulties and challenges that older customers face in a supermarket environment in China, so as to understand the way in which the supermarket environment and service can improve older customers' shopping experience. An ethnographic user study, which combines video-based direct observations, in-depth interviews and a cultural probe information gathering pack, has been employed to explore Chinese older customers' supermarket shopping experience. 30 Chinese senior citizens above 65 years of age and able to undertake their own shopping at least once fortnightly participated this project. Research results show that a shopping experience design should not only concentrate on instore shopping, but on a holistic shopping experience that includes shopping preparation, journey to store, in store shopping, journey back to home and after shopping at home. This flow and journey needs to be understood and addressed when designing a supermarket service for older customers. The supermarket shopping related issues that older Chinese customers face have been summarised, reported and discussed in the paper.

keywords: supermarket service design; older Chinese customers; ethnographic user study 


\section{Introduction}

The population of the world is ageing. The number of people classified as old in the world could rise to over 2 billion by 2050 (ONS, 2013). As the biggest economy in the world, it has been forecast that China will see an increase of $22 \%$ in the proportion of people aged 60 years and over, from $13 \%$ ( 185 million) to $35 \%$ (487 million) of the total population between 2012 to 2053 and this increase will be the fastest in the world (World Population Ageing Report, 2013).

Because of this substantial global demographic shift, numerous studies have been conducted to improve ageing people's quality of life from multiple perspectives such as public service, transportation services, health and social care, product and service design, and the pension system (Stewart, et al, 2014; Li et al, 2012; Kim et al, 2011). Among these studies, many researchers have highlighted the importance of shopping in older people's day-to-day life and have discussed older customers' shopping behaviour and retail needs (Yin et al, 2013; Thompson et al, 2011; Meneely et al, 2009). Several researchers have identified characteristics of older customers' shopping habits that differentiate them from their younger counterparts, such as decreased price sensitivity, preferences for quality products, a tendency to make joint buying decisions and greater levels of store loyalty (Kohijoki, 2011). These factors play a significant role on their shopping experience and satisfaction. Thus a better understanding of consumer shopping habits and behaviour within and between age cohorts can be used to inform the best types of service provision for the ageing shopper (Angell et al, 2012).

Although the findings from previous research on older shoppers are notable, research gaps still remain. Existing studies have improved the knowledge of older shoppers' needs, but previous work has mainly focused on America (Lu and Seock, 2008), Australia (Worsley et al., 2011), New Zealand (Goodwin and Mcelwee, 1999), UK (Omar et al, 2014; Yin et al, 2013) and other and European countries (Kohijoki, 2011), whilst research in developing countries, such as China, has been minimal (Liu, 2014). Chinese older customers' shopping habits and behaviours tend to be different compared to customers in the West owing to cultural and other differences, such as fewer Chinese older customers drive to stores, the rituals of morning exercise as well as diverse supermarket formats in China (Maruyama \& Wu, 2014). Thus, in order to serve this market effectively, retailers need to develop a good understanding of older Chinese customers' shopping habits, unmet needs and requirements for supermarket service. Therefore, this research aimed to investigate what challenges and difficulties that elderly Chinese consumers currently face during their supermarket shopping process, and how to improve supermarket service and environment from a design viewpoint.

\section{Literature review}

\section{Older people in China}

In China, the challenge of population ageing is an emergent area of concern with significant implications as the country enters a period referred to by some as 'super ageing' (Liu, 2014). This has raised several challenges for the Chinese government. For instance, the cost of home and social care for this demographic group and public services that support their living independence has increased dramatically in the past decade (Sun et al, 2014). Researchers have also noted that ageing encompasses social changes that 
lead the elderly to have different requirements and preferences to public services in their day-to-day life (Park and Farr, 2007). For instance, older people need to be more independent and rely more on public services compared to previous generations due to changes in family structure and domestic migration in China (Flaberty et al, 2007; Biao, 2006). As a result, based on the 2010 Chinese Census, Liu et al (2015) have highlighted that the number of 'left-behind' elderly has been increasing; $31.8 \%$ of older people do not live in families and within that $15.4 \%$ live with a spouse and $16.4 \%$ live alone.

Consequently, these older people cannot rely on traditional family care any more, having to take care of themselves and be more independent. Much research has emphasised the importance of supermarket shopping in older people's life (Omar et al, 2014). It not only contributes to health and wellbeing, but also determines the older peoples' sense of independence that has been considered to be mentally important to consumers as they become older (Brennan and Ritch, 2010). As most of the existing literature on older shoppers is focused on Western countries, it is necessary to explore and understand older Chinese customers' supermarket shopping experience and their unmet needs towards supermarket service. In this study, therefore, the older customers have been identified as Chinese customers who are aged over 65 years old.

\section{Retail environment in China}

Retail formats in China can be categorized into two groups, traditional retail format and modern retail format. The former includes wet market, traditional grocery stores and specialty food stores (e.g. butchers, staple food stores and general stores), and the latter includes, convenience chains, small stores, supermarkets and hypermarkets (Maruyama \& $\mathrm{Wu} ; 2014)$. Some researchers have highlighted that although traditional markets such as wet markets are perceived as offering superior freshness, low price and the chance to barter and bargain, the traditional markets are usually untidy and less organized, with weak regulations and poor food safety which is often a major concern for consumers (Gorton et al., 2011). In contrast, modern format stores are often better managed and under government regulation so product safety is more likely to be guaranteed (Goldman et al., 1999). Thus, despite traditional markets/stores providing unique value to customers in China, more and more older Chinese customers prefer to conduct their shopping in modern supermarket stores (Cui and Liu, 2000). Thus, this study focused on an exploration of older customers' supermarket shopping experience.

\section{Supermarket shopping related issues that older customers face}

Much of the research into this area has taken place within the western context and investigation within China has been minimal (Liu, 2014). Based on current knowledge, older people's shopping experience is directly influenced by supermarket design. For instance, layout, lighting, product information, shopping facilities, accessibility, location, temperature, service, smell and ambience all play an important role in the shopping experience (Woodliffe, 2007). Despite recognizing the importance of this customer segment, previous research indicates that most retailers fail to provide this group with a satisfying shopping experience (Brown et al., 2008). In the light of this shortfall, recent research by Yin et al (2013) indicate that important shopping related factors can be classified within six categories: trolleys and baskets, store layout and aisles, shelves and freezer, product related issues, customer service and checkout. For example, studies by Goodwin and McElwee (1999) also revealed that short queues, access to discounts, good customer service and easy parking were important factors for them. 


\section{Methodology}

In order to investigate the supermarket shopping related difficulties and challenges that older consumers face in China, an ethnographic user study approach that includes videobased direct observation, in-depth interviews and a cultural probes information gathering pack were employed. This methodology was chosen, as it would support the researchers in studying people's behaviour within a natural setting over a relatively long period of time. It also represents a dynamic picture of the lifestyle of the targeted elderly consumer group (Burns, 2000). The key feature of an ethnographic study is its capacity to view a phenomenon through the eyes of the user so as to discover the user's needs (Hughes et al, 2004). Thus, it is very useful in designing service to satisfy the end-user, the elderly consumer in this case.

1) A video-based direct observation method was chosen because it supports the researchers in discovering and discussing the real, indisputable actions of the elderly consumer's shopping behaviour as they occur (Berg \& Lune, 2012). It helps the researchers to capture and fix 'reality' contextually.

2) An in-depth interview approach was also chosen because it offers a great opportunity for the researcher to understand individuals more deeply and to open up new dimensions of the problem and secure vivid, rich information that is based on personal experiences (Easterby-Smith et al 2002). It supported the researchers in understanding older customers' emotional feeling, satisfaction and thought processes during their shopping process. During the interview process, the shopping video was used as a supportive reminder for the participants in recalling their shopping experience when it was necessary. Combining direct observations and in-depth interviews allowed the researchers to not only capture older shoppers' natural shopping behaviours but also understand the reasons behind their behaviour.

3) Cultural probes are tools for collecting (usually qualitative) data. Also known as 'diary studies', or 'design probes' in design research, cultural probes are helpful for collecting data about people's everyday lives over a significant time period and when the researcher cannot be present. This method has been used widely in user-centred design research, and has potential for use in social science too (Gaver, B. Dunne, T. and Pacenti, 1999; Mattelmaki, 2006). In this study, a cultural probes box, that includes instruction book, diary, shopping experience evaluation cards and some post-it, has been applied to explore the shopping experience from the participant's viewpoint.

- Instruction book: how to use the box for data collection

- Diary: to explore impact of shopping in people's day-to-day life

- Supermarket evaluation cards: to examine participants' shopping experience

- Post-it: for extra notes

The sample size for the ethnographic study is normally smaller and can be varied based on research objectives and practical factors. Many researchers have suggested that often only a relatively small sample is needed for an ethnographic study. This can be between 5 to 30 participants (Bernard, 2002; Brown \& McCormack; 2005). For this study, participants had to be above 65 years old and able to undertake their own food shopping at least once fortnightly. This ensured that they were mentally and physically capable of completing the research experiment. Participant recruitment information was disstimented through local ageing realted groups, such as elderly clubs and elderly dancing groups. In total, there 
were 30 participants in the user study. Nanjing, Qingdao and Chongqing were selected as research regions for the user study because they have a comparatively high proportion of people aged 65 and over in China (National Bureau of Statistics of China, 2011). 10 participants from each of the three research regions were invited.

The user study was designed to last six weeks in order to balance richness of data collection and feasibility/availability of participants' engagement. After older shoppers agreed to participant the user study, the researchers gave them a cultural probes box and gave an explanantion on how to use items in the box to record their shopping experience. The participants were required to complete at least 4 diaries per week to record their daily activities that included both shopping related and non-shopping related events. With the intention of collecting a balanced feedback that covered most components of a supermarket service, shopping evaluation cards were designed with six weekly-based focuses, probing areas such as: Layout, baskets and trolleys; Shelving and product display; Products and promotions; Comfort and services; Customer service; and Checkouts.

Under each of the six focuses, there were three shopping evaluation cards: List It, Dream It and Rank It.

- List it: to list issues of supermarket service and design

- Dream it: to describe how supermarket service and design can be improved

- Rank it: to score the current supermarket service with 1-5 starts

During the 6-week user study period, apart form the cultural probes pack, the researchers visited the participants twice for shopping observations and in-depth interviews. The participants were asked to conduct their shopping in a natural way and they were observed from a distance. A small size video recorder was used for data collection to reduce the level of unavoidable disturbing of video recording to participants' shopping process. Immediately after shopping observations, the participants were interviewed to elicit their feelings and satisfaction levels. The interviews were conducted at a quiet and safe space such as the participant's house, store office or a quiet coffee area. The interview was based on the participant's shopping journey and experiences within the supermarket, without any set sequence of discussion. All conversations were based on the participant's shopping experience. The observations took between 30 minutes to 1.5 hours and the interviews were between 45 minutes to 2 hours. In some instances, some participants were only visited once due to unexpected issues such as illness. Overall, the results from the user study data collection were based on 42 store visits.

\section{Data analysis}

Content analysis was selected as an analytical method for this project because it emphasises natural and empirical content rather than interpretative arguments. It has been seen as one of the most objective methods for the study of consumer behaviour and culture (Seale, 2004). The principal strength of this approach lies in the clear and systematic study of qualitative content as a basis for analysis and interpretation. This methodology helps to bring out some of the subtler nuances of the older customers' shopping behaviour that cannot be captured easily such as personal values and physical discomforts. According to Blaxter et al. (2001), the process of analysing data involves reducing the size and scope of information, translating this into a more useful form for the study. This was achieved through coding where the data was simplified, standardised and reduced into groups. Selection was then used to identify significant clusters to illustrate key points emerging from the research (Miles and Huberman, 1994). 


\section{Key Findings}

\section{Participants' background}

Among the 30 older customer participants, there were 13 males and 17 females. 20\%

$(\mathrm{N}=30)$ of the participants aged between $65-69$ years old, $46 \%(\mathrm{~N}=30)$ aged between $70-74$ years old and $33 \%(\mathrm{~N}=30)$ aged over 85 years old. 27 of the participants have self-reported as very good and good with regards to their health in general, 13 of them selected fair to represent their health situation. 4 of the participants live alone and the rest of them live with either spouse, Children or together. Most of them $(73 \%, N=30)$ do grocery shopping between 2-6 times per week. Their average weekly spending on grocery shopping are evenly distributed, $30 \%(\mathrm{~N}=30)$ of the participants spent less then $\mathrm{f} 20$ on grocery shopping per week, $23 \%(N=30)$ of them spent between $£ 21$ to $£ 49$ and $27 \%(N=30)$ of them spent between $£ 50$ to $£ 99$.

\section{Reasons to shop at supermarkets}

The 30 participants in this study indicated that they normally do their grocery shopping at supermarkets and open markets stores. 20 of the participants highlighted supermarkets stores are their main grocery shopping venue as they believe that supermarkets provide a better shopping environment, good quality of food in terms of freshness and safety, a wide rang of product selection, easy access by walking or public transportation service, good promotion deals and loyalty card service for saving money. For example, some participants indicated that, for certain types of foods such as milk, cooking oil, rice and meat, they only purchase them from supermarkets due to food safety concerns. They believe that supermarkets have a stricter product check policy than open market sellers and local stores, so they have a higher level of trust with foods from supermarkets. Many of them highlighted the fact that although prices are still important to them, they prefer to pay more for high quality foods, which are more important to their health and wellbeing. Many of the participants appreciate benefits of their store loyalty cards that help them to save a good amount of money on grocery shopping than other types of retail formats. 10 participants who have supermarkets as their second tier shopping venue explained that as food prices at supermarkets are higher than the open market they prefer to shop more at open market. In addition, they think they can get fresher vegetables from morning open markets at a cheaper price. The results show the current older generation has inherited a good habit of thrift from the previous generations. However, they are more concerned about the health and safety issues regarding foods. This finding shows that the current food safety issues in China due to illegal food additives and contamination with environmental hazards have influenced older customers' confidence of foods quality from open markets and local stores (Lam et al, 2013). It also reflects that the current older generation has greater purchasing power and is less likely to shop at discount retailers in the future, especially as they prefer a 'high quality product and pleasant shopping environment' (Hare, 2003). Food safety has been rarely discussed older customers' supermarket shopping experience in the western context in the last decade. This may be because trust in the food safety of supermarkets has been established over a long period of time, making it less of a research area to consider. Schutz \& Bruhn (1999) stated that $86 \%$ ( $n=592)$ customers are either completely or somewhat confident about the safety of food from supermarket. However, food safety is 
reported to an important concern in Asia, in countries such as Vietnam and Malaysia (Wertheim-Heck \& Spaargaren, 2015; Siow \& Sani, 2011).

\section{Preparation for shopping}

In order to have a smoother shopping experience, older customers normally take several assistive items with them to stores. For example, some participants indicated reading glasses are very important for their shopping as it would be very difficult for them to read labelling and product information without it. Other items have been mentioned include shopping list, shopping bags, foldable shopping trolley with wheels, mobile phone, keys, cash/wallet, travel card, store loyalty cards, shopping cards/gift cards and medicine for emergency use. Bad weather could change people's shopping plans. One participant mentioned that 'If the weather is not good, and it is raining, I will not continue with my plan to shop'. Almost half of them do not plan for shopping. This could be because they normally visit supermarkets several times during the week, so a planned large shopping visit is unnecessary. However, in the western context, Meneely et al (2009) indicated that more than $70 \%(n=791)$ older customers plan their shopping a week ahead. Many of the participants mentioned that they go to supermarket not only for shopping but also to exercise, by walking there and by walking around the store. Most older coustomers take shopping as one of the most important social activities in the west (Smith and Sparks, 2000), but, very few of them view shopping as a physical exercise. 10 of the participants said they do prepare a shopping list before they go shopping due to their memory problems. Most of them prefer to have fresh food rather than keep foods for too long. One participant said, 'we normally buy foods based on the next day meal plans. I would not keep the food for too long, as it may turn bad quickly'. Budget has also been indicated as a part of shopping preparation. Participants indicated that they would only take a certain amount of money they need for shopping as they worry that they may lose the money. One participant said 'I know what I need to buy, I usually take $£ 10$ or $£ 20$ with me for the shopping'. Comparing with the western older customers, Chinese older shoppers prefer to use cash or gift cards for payment and very few of them use cedit cards at the checkout counter.

\section{Journey between home and store}

$40 \%(N=30)$ of the participants go to supermarket mainly by walking, $40 \%(N=30)$ of them mainly by buses, and the rest mainly cycle to shop. Due to mobility and health issues, public transportation is one of the key elements older customer consider when selecting shopping stores. Many participants mentioned that they prefer to shop with supermarkets that are close to bus stations rather than the nearest store. Some participants felt that buses are safer than walking or cycling and they can have a rest on the bus on during the journey. Some complained about the traffic light system that does not offer enough time for older people to cross the road. Furthermore, public bus service is free or cheaper for people aged over 60 years old depends on regions in China, this encourages older shoppers to take buses for shopping. Some other participants indicated they prefer walking to store, as this is a good way of exercise. One participant said 'It takes me around one hour to walk to the store that I normally go to. My children suggested that I take the bus, but I think this is good to my health'. Participants who selected cycling think riding a bike is very convenient and helpful for this shopping journey. 
However, it is not easy to ride a bicycle with all shopping items on the way back home. Thus, some participants indicated that they would hang the shopping bags on the bicycle and then push it on the journey back. Store accessibility has been discussed within the western context. In Hare et al's (1999) study, they found that the majority of their older participants who responded to store accessibility questions indicated negative experiences with transport and support. All the 30 participants in this particular study do not drive for shopping as they don't know how to drive or have no access to a car in the household. However, in the western context, most of the older people drive for shopping, including people aged over 80 years old. For example, Meneely et al (2009) claimed that $29 \%(n=143)$ of their $80+$ years old participants drive to a store for shopping.

\section{In-store shopping}

Issues of in-store shopping focus on trolley, basket, shelf and layout, promotion, customer service and checkout. For example, the participants complained that trolleys were hard to control, too big and too deep. They suggested that it would be better if a smaller sized and better-designed trolley could be provided. Many of the participants think that a shopping basket is too heavy to carry around the store and they prefer a basket with wheels and handle. Regarding shelf and layout, many participants complained about the difficulties in finding products due to poor navigation signage design, picking up products from the top and bottom levels of shelf, products and labels on shelf are not consistent, labels were too small to read and product display that kept changing. One participant said that 'the shelf is too high, around 2 meters. It is impossible for me to pick up items form the top shelf'. Other older shoppers suggested that 'heavy products such as cooking oil should be allocated on easy access shelf'. Participants also suggested using colour coding for store layout. Regarding promotions, many of the participants felt that prices for promoted products were confused, dates for promotion period was not clear and the quality of the promoted product might not good. Also, some participants indicated promoted products were always in a big package that was too large and too heavy for older people. Feedback to customer service was mainly focused on over-selling by sale assistants, lack of staff on the floor, impatience when answering an older customer's questions and indifferent staff who ignored older people's needs. They also felt that a shuttle bus can be improved to extend its service catchment area so more older people can gain benefit this service. Participants further explained that some brands hired sale assistants to promote their products in store. These sale assistant always over-sell products and do not care if the product is right for older customers according to their needs. Issues with checkout include long queues, narrow checkout aisles, lack of staff at checkout, lack of friendliness at the checkout (no smiles) and no packing service. Many instore shopping related issues that arose within this study have also been reported from exisiting studies, for example, difficulties of using trollerys, shelf is too high or too low and package related problems(Omar et al, 2014; Angell et al, 2012; Kohijoki, 2011). This could be a result of human factors and physical limitations and less to do with cultural differences.

\section{After shopping at home}

Most of the participant expressed tiredness once they arrived home from shopping. Thus, many of them suggested that a supermarket should provide a 'deliver to home' service for older people. During the unpacking process, some of the participants put all shopping 
items into the right places such as the storage cupboard and fridge in one go; some other participants normally put all foods in the kitchen first for cooking and then allocate the rest of shopping items to the right places after cooking. After unpacking, many of participants reused plastic shopping bags as bin bags.

\section{Suggestions to improve supermarket service}

Based on the cultural probes 'Dream it' cards, many suggestions for improving supermarket service for older customers have been given. Some participants indicated that the current trolley design was not very user friendly to people with different heights. Tall people find it difficult to push the trolley, whereas short people feel that the trolley is too deep for reaching items on the bottom. They proposed that a trolley should have adjustable height that would satisfy different types of customers. One participant highlighted the safety issues of leaving personal items within a trolley. She said 'I would not leave my bag in the shopping trolley as my wallet was in my bag'. She recommended that a personal locker should be designed on a trolley. Another trolley related comment suggested the addition of a brake on the trolley so customers could stop a trolley effectively and easily when they needed to. Some other participants commented that on the wheelie/pull-along shopping basket, the handle was too thin and uncomfortable for holding. It would be better to have a wider designed holding position on the handle. For store layout design, some participants suggested that the fresh food zone should be close to a store entrance and navigation signage should be clearer. One participant suggested that the supermarket should redesign its layout based on a customer's purchasing power and another advised that they should provide a special zone for older people similar as the current baby zone in the store. For multi-floors store, older customers would like to have grocery products on the ground floor so they do not have to go the different floors for shopping. For customer service, many participants have suggested staff training is essential for supermarket customer service quality. Supermarkets also should provide a reward system to acknowledge and encourage well-preformed staff so as to improve customer service quality.

\section{Conclusions}

This study explored Chinese older customers' holistic supermarket shopping experience that include home preparation, travel to store, in-store shopping, travel back to home and after shopping at home. Some of the identified shopping issues have been reported in western-based literatures. For instance, trolleys can be difficult to use (Angell et al, 2012) but carrying baskets has been found to cause most difficultly when shopping (Leighton and Seaman. 1997), Hare et al (1999) indicated that wider aisles are important to older customers and Meneely et al (2009) highlighted that older customers felt disadvantaged with multi-purchase promotions. However, most of the existing studies only focused on in-store shopping experience. Based on results from this research, it is clear that older customers' shopping experience is not only related to in-store shopping but also the other parts of their shopping journey. A lack of preparation might cause a difficulty in shopping at a store, such as forgotten reading glasses. Bad weather may stop older peoples' shopping plans and the public transport service may help the older customers to decide which store to visit. Therefore, retailers need to consider older customers' holistic shopping journey so as to explore their unmet needs and then improve supermarket service to Chinese older customers accordingly, whose needs and wants differ from the normal supermarket shopping experience in the west, where many older shoppers will have access to cars. The study highlights many important aspects for designing the 
supermarkets of the future, when many of the shoppers are likely to be older than the normal population in China.

\section{References}

Angell, R., Megicks, P., Memery, J., Heffernan, T. and Howell, K. (2012). Understanding the older shopper: a behavioural typology. Journal of Retailing and Consumer Services, 19, 259-269.

Berg, B.L. and Lune, H. (2012). Qualitative Research Methods for the Social Sciences (Eighth Edition). USA: PEARSON.

Bernard, H. (2002). Research Methods in Anthropology: Qualitative and Quantitative Approaches, Third Edition. New York: Altimira Press.

Biao, X. (2006). How far are the left-behind left behind? A preliminary study in rural China. Population, Space and Place, 13, 179-191.

Blaxter, L., Christina, H. and Tight, M. (2001). How to Research (2nd ed.) Milton Keynes: Open University Press.

Brennan, C. and Ritch, E. (2010). Capturing the voice of older consumers in relation to financial products and services. International Journal of Consumer Studies, 34, 212-218

Brown, D. and McCormack, B. (2005). Determining factors that have an impact upon effective evidence-based pain management with older people, following colorectal surgery: an ethnographic study. Journal of Clinical Nursing, 15 (10), 1287-1298

Brown, K., Denham, P., Edwardson, J., Kuznesof, S., Lax, A., Richardson, E., von Zglinicki, T. and Weiner, B. (2008). Design for all, for life, North East Regional Forum on Ageing, Institute for Ageing and Health, Newcastle University, Newcastle.

Burns, R.B. (2000). Introduction to Research Methods. London: Sage

Cui, G., and Liu, Q. (2000). Regional market segments of China: opportunities and barriers in a big emerging market. Journal of Consumer Marketing, 17(1), 55-72.

Easterby-Smith, M.P.V., Thorpe, R. and Lowe, A. (2002). Management research: an introduction (Second Edition). London: SAGE.

Flaberty, J. H., Liu, M.L., Ding, L., Dong, B., Ding, Q., Li, X. and Xiao, S. (2007). China: The Aging Giant. Journal of the American Geriatrics Society, 55, 1295-1300

Gaver, B. Dunne, T. and Pacenti, E. (1999). Cultural Probes. Interactions, (February), 21-29.

Goodwin, D. R. and McElwee, R. E. (1999). Grocery shopping and an ageing population: research note. International Review of Retail, Distribution \& Consumer Research, 9(4), 403-409.

Gorton, M., Sauer, J. and Supatpongkul, P. (2011). Wet markets, supermarkets and the Big Middle for food retailing in developing countries: evidence from Thailand. World Development, 39(9), 1624-1637.

Hare, C. (2003). The food-shopping experience: a satisfaction survey of older Scottish consumers. International Journal of Retail \& Distribution Management, 5,244-255.

Hare, C., Kirk, D. and Lang, T. (1999). Identifying the expectations of older food consumers - more than a "shopping list" of wants. Journal of Marketing Practice: Applied Marketing Science, 5(6/7/8), 213-232.

Hughes, G., Bennett, K. and Hetherington, M. (2004). Old and alone: barriers to healthy eating in older men living on their own. Appetite, 43 (1), 269-79.

Kim, N.H., Hoyek, G.E. and Chau, D. (2011). Long-term care of the ageing population with intellectual and development disabilities. Clinics in Geriatric Medicine, 27(2), 291-300.

Kohijoki, A. (2011). The effect of ageing on consumer disadvantage in grocery retail services among the Finnish elderly. Journal of Retailing and Consumer Services, 18, 370-377.

Lam, H., Remais, J., Fung, M., Xu, L., Sun, S.S. (2013). Food supply and food safety issues in China. The Lancet, Vol.381, Issue 9882, 8-14 June, 2044-2053

Leighton, C. and Seaman, C. (1997). The elderly food consumer: disadvantaged? Journal of Consumer Studies and Home Economics, 21, 363-370. 
Li, H., Raeside, R., Chen, T. and McQuaid, R.W. (2012). Population ageing, gender and the transportation system. Research in Transportation Economics, 34(1), 39-47.

Liu, J, Tian, J, Yue, P., Wang, Y., Du, X. and Chen, S. (2015). Living experience and care needs of Chinese empty-nest elderly people in urban communities in Beijing, China: A qualitative study.

Liu, J. (2014). Ageing, migration and familial support in rural China. Geoforum, 51, 305-312

Lu, Y. and Seock, Y.K. (2008). The influence of grey consumers' service quality perception on satisfaction and store loyalty behaviour. International Journal of Retail \& Distribution Management, 36 (11), 901-18.

Maruyama, M, and Wu, L. (2014). Quantifying barriers impeding the diffusion of supermarkets in China: the role of shopping habits. Journal of Retailing and Consumer Services, 21, 383-393

Mattelmaki, T. (2006). Design Probes. Helsinki: Univerisity of Art and Design Helsinki.

Meneely, L., Burns, A. and Strugnell, C. (2008). Food retailers' perceptions of older consumers in Northern Ireland. International Journal of Consumer Studies, 32, 341-348.

Meneely, L., Burns, A. and Strugnell, C. (2009). Age associated changes in older consumers retail behaviour. International Journal of Retail and Distribution Management, 37(12), 1041-1056

National Bureau of Statistics of China (2011). Report of the sixth national population census. Retrieved August 20, 2012, Retrieved from http://gb.cri.cn/27824/2011/08/22/3245s3345142.htm (In Chinese)

Omar, M., Tjandra, N.C. and Ensor, J. (2014). Retailing to the "grey pound": understanding the food shopping habits and preferences of consumers over 50 in Scotland. Journal of Retailing and Consumer Services, 21, 753-763

ONS (2013). National population projections, 2012-based, Office for National Statistics. Retrieved from http://www.ons.gov.uk/ons/dcp171778_334975.pdf

Park, N. and Farr, C. (2007). Retail store lighting for elderly consumers: an experimental approach. Family and Consumer Sciences Research Journal, 35(4), 316-337.

Seale, C (2004). Researching Society and Culture (2nd ed.). London: SAGE

Siow, O.N. and Sani, N. A. (2011). Assessment of knowledge, attitudes and practices (KAP) among food handlers at residential colleges and canteen regarding food safety. Sains Malaysiana, 40 (4), pp. 403-410

Stewart, J., Crockett, R., Gritton, J., Stubbs, B.and Pascoe, A. (2014), Ageing at Home? Meeting Housing, Health and Social Needs, Journal of Integrated Care, 22 (5/6), pp.242-252

Sun, J., Deng, S., Xiong, X. and Tang, S. (2014). Equity in access to healthcare among the urban elderly in China: does health insurance matter? The International Journal of Health Planning and Management, 29, 127-144

Thompson, J.L., Bentley, G., Davis, M., Coulson, J., Stathi, A. and Fox, K.R. (2011). Food shopping habits, physical activity and health-related indicators among adult aged $\geq 70$ years. Public Health Nutrition, 14(9), 1640-1649.

Wertheim-Heck, S.C.O., Spaargaren, G. (2016). Shifting configurations of shopping practices and food safety dynamics in Hanoi, Vietnam: a historical analysis. Agriculture and Human Values, 33(3), pp.655-671

Woodliffe, L. (2007). An empirical revaluation of consumer disadvantage. International Review of Retail, Distribution and Consumer Research, 17 (1), 1-21

World Population Ageing Report (2013). World Population Ageing 2013. United Nations. Retrieved fromhttp://www.un.org/en/development/desa/population/publications/pdf/ageing/WorldPopul ationAgeing2013.pdf

Worsley, T., Wang, W.C. and Hunter, W. (2011). Baby boomers' reasons for choosing specific food shops. International Journal of Retail \& Distribution Management, 39 (11), 867-882.

Yin, Y., Pei, E. and Ranchhod, A. (2013). The Shopping Experience of Older Supermarket Consumers. Journal of Enterprise Information Management, 26, (4), 444-471 
Dr. Yuanyuan Yin is a Lecturer at Winchester School of Art, University of Southampton. Her research concentrates on promoting business performance through developing design and brand strategies, understanding customers/ users, supporting design collaboration, and product design innovation.

Song Qiu is a Professor in Design at Academy of Arts and Design, Tsinghua University, Supervisor of PhD students, Director of Basic Courses Teaching \& Research Office and DMI member. His research focuses on innovation, design and branding strategies.

Dr. Ashok Ranchhod is Principal Teaching Fellow in Marketing Communications within Winchester School of Art at the University of Southampton. His research focuses on Branding, Serious Games Design and Marketing Communications, $\mathrm{He}$ has published extensively in these areas. 